\title{
Author Correction: Revealing the mechanism for covalent inhibition of glycoside hydrolases by carbasugars at an atomic level
}

\author{
Weiwu Ren (1) ', Robert Pengelly², Marco Farren-Dai', Saeideh Shamsi Kazem Abadi , Verena Oehler², \\ Oluwafemi Akintola1, Jason Draper ${ }^{1}$, Michael Meanwell', Saswati Chakladar ${ }^{1}$, Katarzyna Świderek (D) ${ }^{4}$, \\ Vicent Moliner (iD ${ }^{4}$, Robert Britton', Tracey M. Gloster (i) ${ }^{2} \&$ Andrew J. Bennet (i) $^{1}$
}

Correction to: Nature Communications; https://doi.org/10.1038/s41467-018-05702-7; published online: 13 Aug 2018

In the originally published version of this article, the affiliation details for Tracey M. Gloster were incorrectly given as 'Department of Molecular Biology and Biochemistry, Simon Fraser University, 8888 University Drive, Burnaby, BC V5A 1S6, Canada'. The correct affiliation is 'Biomedical Sciences Research Complex, University of St. Andrews, North Haugh, St. Andrews, Fife KY16 9ST, UK'. This has now been corrected in both the PDF and HTML versions of the Article.

Published online: 07 September 2018

\begin{abstract}
(c) (i) Open Access This article is licensed under a Creative Commons Attribution 4.0 International License, which permits use, sharing, adaptation, distribution and reproduction in any medium or format, as long as you give appropriate credit to the original author(s) and the source, provide a link to the Creative Commons license, and indicate if changes were made. The images or other third party material in this article are included in the article's Creative Commons license, unless indicated otherwise in a credit line to the material. If material is not included in the article's Creative Commons license and your intended use is not permitted by statutory regulation or exceeds the permitted use, you will need to obtain permission directly from the copyright holder. To view a copy of this license, visit http://creativecommons.org/licenses/by/4.0/.
\end{abstract}

(C) The Author(s) 2018

\footnotetext{
${ }^{1}$ Department of Chemistry, Simon Fraser University, 8888 University Drive, Burnaby, BC V5A 1S6, Canada. ${ }^{2}$ Biomedical Sciences Research Complex, University of St. Andrews, North Haugh, St. Andrews, Fife KY16 9ST, UK. ${ }^{3}$ Department of Molecular Biology and Biochemistry, Simon Fraser University, 8888 University Drive, Burnaby, BC V5A 1S6, Canada. ${ }^{4}$ Department de Química Física i Analítica, Universitat Jaume I, 12071 Castellón, Spain. Correspondence and requests for materials should be addressed to R.B. (email: rbritton@sfu.ca) or to T.M.G. (email: tmg@st-andrews.ac.uk) or to A.J.B. (email: bennet@sfu.ca)
} 